\title{
LA CONCIENCIA METAPOÉTICA EN UN POEMA DE JORGE EDUARDO EIELSON
}

\begin{abstract}
Alex Morillo Sotomayor*
La palabra — la palabra del poeta — está creando el mundo desde adentro. Es luz y construcción, es carne y hueso del espíritu. J. E. Eielson
\end{abstract}

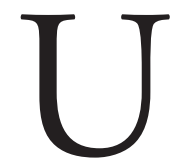

na poética como la de Jorge Eduardo Eielson (Lima, 1924-Milán, 2006), la figura más representativa de la generación del cincuenta, exige a toda aproximación crítica redefinir los conceptos con los que usualmente construye la imagen de poesía y de poeta.

La compleja y fascinante escritura poética de Eielson es eminentemente transformacional, más aún en el momento que despliega su mirada sobre sí misma. Dicho despliegue se materializa en una conciencia metapoética, originando una suerte de escritura de la escritura que da cuenta de una idea más amplia de la poesía, buscando aprehenderla como significación terminada — el poema — , acto de dar sentido —el poetizar-

Docente del Área de Comunicación y Producción del Lenguaje del pregrado UCSS. Dicta el taller de lectura literaria de la UCSS. 
y/o modo de vida —el estado poético—. Nuestro objetivo en las siguientes líneas es desentrañar el entretejido de esta triple aprehensión a partir de un breve análisis del poema "Arte poética 1", perteneciente a Arte poética (1965). Pero antes de que exploremos las estrategias de atadura y desatadura de sentidos que el lírico pensador ${ }^{1}$ plasma en el poema, creemos necesario destacar algunas consideraciones fundamentales.

Sustentamos, en primer lugar, que la poética eielsoniana está íntimamente ligada a dos tipos de culto: el primero tiene que ver con un culto a la esencia de las cosas, reconocible desde una praxis creativa que gira en torno a la transformación, la contrariedad, la renovación, la imposibilidad, la simplicidad, el énfasis, la inversión, el silencio, la autocontemplación, la regeneración, entre otros. Todos estos factores forman parte del estado de la expresión de dicha poética. El segundo culto, consecuencia inmediata del primero, es a la tensión de la dimensión semántica y formal de los poemas, que convierte el hecho de referir poéticamente en una expresión fronteriza que transgrede la convencionalidad y la arbitrariedad del símbolo para dar paso a un despliegue de sentidos que busca resaltar el carácter ambiguo y fragmentario de la palabra, despojándola, así, de todo retoricismo envolvente. Ambos cultos coinciden en un claro propósito desmitificador sobre la relación entre el referente, el soporte y la herramienta del hacer poético, factores que necesitan vivificarse a través de nuevos mecanismos de

1 Siguiendo a Hugo Friedrich, el poeta moderno se constituyó como un lírico pensador que se preocupaba cada vez más por la posesión de una conciencia de la forma, de este modo el acto creativo se convirtió en una actividad que se observaba a sí misma. La generación del discurso poético partía, entonces, de una suerte de autocontemplación: la "escritura de la escritura» o el «monólogo» de la palabra no escapaba de su propia referencialidad. En la poética contemporánea de Eielson, este principio adopta una presencia constante, hasta el punto de que podemos reconocerla en su producción total con distintas formas de realización, pero integradas todas ellas en lo que llamamos la construcción de una conciencia metapoética. 
convivencia donde no hay lugar para un consenso o reconciliación con el lenguaje, si es que este no apunta a una comunión con un todo significante. Si es que a la poesía no se le entiende como «el estado permanente del universo", diría Eielson. De este modo, la poética eielsoniana establece una relación activa, mas no mimética, con lo real, al gestar una referencialidad provista de dobles intencionalidades: sobre sí misma y sobre el mundo, sobre lo particular y lo universal, sobre lo concreto y lo intangible. Para Eielson, lo real acontece en el discurso sea cual sea el código en el que este se sustente. Por tal motivo, nuestro autor supera, con un admirable don creativo, la polarización que convencionalmente separa ambas dimensiones.

En segundo lugar, es imperativo precisar que el surgimiento de la conciencia metapoética eielsoniana es indisociable de una visión crítica. Esta visión, aclaremos, presenta diversos matices, dado que aparece en el tratamiento de varios temas; así mismo, se encuentra dispersa en el amplio repertorio creativo y/o reflexivo de Eielson. ${ }^{2}$ No obstante, el tipo de visión que nos interesa aquí es aquel que problematiza la capacidad expresiva del lenguaje y su lógica de lo verosímil desde la objetualización del hacer poético, demandándonos un cambio de actitud en la percepción de este:

2 Sobre la visión crítica presente en otras formas de expresión o géneros, como la narrativa, Sergio R. Franco señala que en las novelas de Eielson, por ejemplo, se apela a determinadas estrategias discursivas para criticar la realidad peruana, estrategias que lindan con la ciencia ficción, lo contrafático, la incoherencia, lo indeterminado, transgrediendo un tipo canónico de verosimilitud en cuanto a los personajes, las acciones, la secuencialidad y los espacios representados (R. Franco 2002: 97-102). Por otro lado, es común encontrar, en sus ensayos, artículos periodísticos y conversaciones sobre arte contemporáneo, reflexiones críticas que reflejan su preocupación sobre los riesgos que este trae consigo y las nuevas tendencias artísticas que van apareciendo. Una muestra de esto es el texto titulado "Arte italiano de los años 90", donde Eielson critica el sistema del arte europeo marcado por una serie de intereses comerciales y lanza una sentencia que ilustra su profunda convicción por la naturaliza humana del arte: «Mientras exista un solo hombre sobre la tierra, existirá siempre el arte» (Eielson 2002a: 217). 
de ser considerado un ejercicio creativo liberado de toda sospecha, ahora se constituye en un punto de referencia más a ser cuestionado desde sus propios dominios internos. Dicho de otro modo, al ser discursivizada la práctica escritural se expone a los rigores de una expresión que explora, siempre renovando, su estado, su naturaleza, en suma, su límite y posibilidad de significar. En ello radica la importancia de esta conciencia: en que delimita su campo de acción referencial sobre, desde, dentro y en torno a la poesía.

Consideramos, en tercer lugar, que la conciencia metapoética es una de las constantes que más ha aportado en la construcción de la identidad poética eielsoniana. En efecto, el desarrollo de esta conciencia, como un motivo creativo gravitante en toda su producción poética, da cuenta de su carácter inmanente y alcance absoluto, es decir de su revelación permanente, a modo de un principio regulador y articulador.

Para Eielson, la poesía es una "pequeña catástrofe organizada al interior del lenguaje» (2002b: 229), por ello, hace explícita su preocupación por lograr una expresión auténtica y su apremiante necesidad de valerse de una superconciencia. Citemos al respecto un fragmento de su ensayo «Manual de lectura»:

El terror de no escribir lealmente (de corazón y de pensamiento) se transformó lentamente en una superconciencia y el entero aparato de mi expresión se detuvo de golpe y me fue necesario desmontarlo, y examinarlo pieza por pieza en busca del trauma, tratando al mismo tiempo de introducir algunas mejoras en su arcaica estructura (Eielson 2002c: 378, énfasis nuestro).

Si existe en la poética eielsoniana un afán por renovar la actitud creativa hacia la autentificación de lo que se poetiza, entonces la conciencia 
metapoética es indisociable también de una mirada que pugna por la esencialidad, en pos de la elaboración de una red de sentidos que se establezca como un puente entre lo real y la dimensión mediática de las palabras a sabiendas de que forma parte de un gesto original, matriz o mítico, una expresión libre de grilletes temporales y espaciales, un discurso de la totalidad como hemos convenido en llamarlo.

Como cuarta y última consideración, sostenemos que la conciencia metapoética eielsoniana posee dos aspectos u orientaciones fundamentales: así, en los textos de Eielson encontramos una particular concepción sobre el proceso escritural, por un lado, y sobre el poeta como agente que lleva a cabo dicha praxis creativa, por el otro. En esta ocasión, y sobre la base de todas las precisiones anteriores, analizaremos el poema "Arte poética 1» de Arte poética (1965), poemario en el que — dicho sea de paso- se da una relación compleja y conflictiva entre el agente creador y el proceso escritural que lleva a cabo, en el marco de una visión crítica sobre la desnaturalización humana en la sociedad moderna, siguiendo la línea de Habitación en Roma (1952) y Noche oscura del cuerpo (1955). Desde una perspectiva general, destacamos de los textos reunidos en este poemario el ritmo fluido y el tono confesional que problematiza aún más o, en todo caso, hace más directa la alusión a una crisis de la palabra siempre insuficiente para la expresión de lo poético. Estos rasgos anuncian la presencia ineludible de una conciencia que da cuenta de un escenario discursivo escindido entre la plenitud del acto referencial y el silencio. En el poema en cuestión, un hablante poético en tiempo presente delimita la extensión de su praxis creativa y proyecta su expectativa de significación en la intensidad que pueda concentrar dicha delimitación. Veamos de qué modo estos aspectos cuantitativos y cualitativos forman parte de una estrategia metapoética: 
He decidido escribir un poema

De cien versos nada más

Y así sin darme cuenta

Tengo ya cuatro líneas negras

Sobre esta página blanca

Que espero sume las necesarias

Antes que se me pasen las ganas

De seguir escribiendo versos

Y comience a mirar la televisión

O a observarme en el espejo

Como lo hago diariamente

Yo que me afeito lentamente

$Y$ cuento mis arrugas con esmero

Esperando vivir largamente

Para de vez en cuando escribir

Algún poema inocente

Posiblemente

Sin mar ni muerte

Y así tengo ya justo veinte

Versos escritos con rima en ente

La voz poética yace inmersa en la dinámica oscilante de escribir y desarrollar actividades cotidianas. Esta dinámica posee, no obstante, una tensión particular desde el sustrato rítmico que adquiere una intencionalidad subvertora mientras va desarrollándose la «empresa extraordinaria» de hacer posible la escritura del poema deseado. La subversión rítmica, que no es otra cosa que una manifestación del ludismo crítico eielsoniano, ${ }^{3}$ crea un paralelo

${ }^{3}$ Frecuentemente, se ha asociado la ironía eielsoniana con una intencionalidad lúdica, pero 
entre la rima consonántica de los versos y el «ritmo vital» del hablante poético (el proceso rutinario de ver televisión, mirarse al espejo, afeitarse y contarse las arrugas). Lo que se logra con esta equivalencia es relievar el efecto de desencanto de ambos devenires rítmicos. La prolongación de la rima somete a la palabra: aquella ya no es más la aliada de esta; es, por el contrario, su carcelera sonora. He allí la paradoja de la intencionalidad subvertora de una voz poética que, poniendo en riesgo su «integridad discursiva», problematiza la praxis creativa que ella misma lleva a cabo anunciando el deterioro y la capacidad mermada que esconde la pretenciosa representación del lenguaje, la «composición preñada/ De versos tintineantes y vacíos», para luego ser absorbida por la imposibilidad del decir. Entonces, podríamos sostener que de la armazón rítmica emerge una sensación de insatisfacción, a modo de una resistencia, silenciosa, que busca la significación esencial y liberada del cautiverio simbólico: «Como si escribir fuera tan sólo/ Ser fundamental/ Tomar aire doctoral/ Colocar la rima al final/ De cada verso y pretender/ De cada uno de ellos el total/ De sonoridad y contenido genial/ Sin darse cuenta que la poesía/ Huye de los poetas/ Como la llama del hollín / Y que al revés de lo que piensa fulano/ En la poesía como en la vida/ Lo principal (hay que ser inteligente)/ No es lo que se queda/ Sino lo que se va» (Eielson 1998: 307310). La conciencia metapoética pretende desmitificar la imagen culta, oficial, elevada que opaca la verdadera experiencia de lo poético, para reconocerla en la trascendencia del devenir, en la posesión y el desprendimiento.

más allá del afán experimental de sus poemas caligramáticos, por ejemplo, o de algunos versos que denotan cierto entretenimiento, soltura o juego, este discurso irónico revela la decadencia moral de la sociedad moderna, claramente representada en los arquetipos humanos víctimas de la alienación consumista, del mismo modo adopta una visión crítica sobre el lenguaje. Por lo tanto, si existe algún sentido lúdico en este tratamiento irónico es a partir de la concepción de un juego en serio, real y consciente, que no tiene nada de superficial, es decir, un juego que nos remite a un ludismo crítico. 
Finalmente, es interesante apreciar cómo algunos versos de este extenso poema van regulando la conciencia metapoética mediante la presencia de marcas deícticas («esta página blanca», «esta rima helada», «esta composición preñada», "esta composición magistral»). Como sabemos, estas marcas o huellas textuales ponen de relieve el plano objetual de la escritura y la funcionalidad pragmática de su soporte. Y al hacerlo, dan cuenta del tener lugar en el lenguaje. Esto es cuando la enunciación poética busca referenciar más allá de los límites textuales, transgrediendo sus coordenadas espaciales y temporales y determinando el fundamento de su propia ambigüedad. Una ambigüedad que en la poética eielsoniana se traduce en la certeza de sospechar sobre lo dicho, puesto que mientras más se cuestione el lenguaje, más transparencia adquiere. En otras palabras, la ambigüedad es mucho más que una señal del lenguaje fragmentado, escindido. Es una apertura hacia la totalidad. 


\section{BIBLIOGRAFÍA}

Eielson, Jorge Eduardo

1976 Poesía escrita. Lima: INC.

1998 Poesía escrita. Santa fe de Bogotá: Norma.

2002a «Arte italiano de los años 90». En Padilla, José Ignacio (editor). nuldo. Homenaje a J. E. Eielson. Lima: PUCP, pp. 215-217.

2002b «La transvanguardia o el talón de Aquiles. Conversación con Achille Bonito Oliva». En Padilla, José Ignacio (editor). nu/do. Homenaje a J. E. Eielson. Lima: PUCP, pp. 223-229.

2002c «Manual de lectura». En Padilla, José Ignacio (editor). nuldo. Homenaje a J. E. Eielson. Lima: PUCP, pp. 378-380.

2004 Artepoética. Edición, prólogo y cronología de Luis Rebaza Soraluz. Lima: PUCP.

CANFIELD, Martha

2002 Jorge Eduardo Eielson. Nudos y asedios críticos (editora). Madrid: Iberoamericana.

Chirinos Arrieta, Eduardo

1998 La morada del silencio. Una reflexión sobre el silencio en la poesía a partir de las obras de Westphalen, Rojas, Orozco, Sologuren, Eielson y Pizarnik. Lima: Fondo De Cultura Económica.

Espezúa Salmón, Dorian

2006 «Mi verdadera, mi única patria es la poesía: aproximaciones a una poética a través de un poema de Jorge Eduardo Eielson». En Tinta Expresa. Lima, N.o 2, pp. 93-108. 
Fontanille, Jacques

2001 Semiótica del discurso. Lima: Universidad de Lima - Fondo de Cultura Económica.

FRIEDRICH, Hugo

1974 Estructura de la lírica moderna. Barcelona: Seix Barral.

González Vigil, Ricardo

2006 «La poesía total de Eielson». En Libros \& Artes, Lima, N. ${ }^{\circ}$ 14-15, pp. 13-17.

Morillo Sotomayor, Alex

2006 «Cuatro anudamientos de la criatura fronteriza: la poética cósmica de Jorge Eduardo Eielson». En Tinta Expresa. Lima, N. ${ }^{\circ}$ 2, pp. 113-134.

Padilla, José Ignacio (ed.)

2002 nuldo. Homenaje a J. E. Eielson. Lima: PUCP.

Ramírez Franco, Sergio

2000 «Las novelas de Eielson». En More Ferarum 5/6. Lima, pp.144152. 